\title{
MOBILITAS NON PERMANEN PENDUDUK NAGARI CANDUANG KOTO LAWEH KECAMATAN CANDUANG KABUPATEN AGAM
}

\author{
Annisa Fultri, Endah Purwaningsih \\ Email: annisa.fultri12@gmail.com \\ endahkusworo@gmail.com
}

\begin{abstract}
Abstrak
Penelitian ini bertujuan untuk mengetahui tentang (1) karakteristik (2) faktor pendorong dan penarik (3)pola pelaku mobilitas non permanen di Nagari Canduang Koto Laweh. Kabupaten Agam Provinsi Sumatera Barat. Jenis penelitian Deskriptif kuantitatif. Teknik analisis data menggunakan rumus persentase. Hasil penelitian (1) penduduk yang melakukan mobilitas non permanen didominasi perempuan, dan usia produktif, serta mahasiswa, pendidikan terakhir dominan SMA, pendapatan dominan Rp.1.100.000,00 - Rp2.000.000,00 (2) faktor yang mendorong penduduk melakukan mobilitas karena di daerah asal sulit mengembangkan usaha dan keterbatasan sarana pendidikan yang ada. Faktor penariknya adalah sarana prasarana dan pendidikan di daerah tujuan lebih lengkap. (3) pola mobilitas didominasi mobilitas sirkuler. Kisaran penduduk bermobilitas selama 1-5 tahun. Waktu tempuh mobilitas yang dominan menempuh waktu $1 / 2-1$ jam .

\section{Abstract}

This study aims to know about (1) The characteristics 2) The push and pull factors (3) Mobility patterns of non-permanent Nagari Canduang Koto Laweh Agam District, Sumatera Barat Province. The type of research is descriptive quantitative research. The data analysis technique is done by using percentage formula.The results of the study are (1) The citizen who do non-permanent mobility is dominated by women, productive age and students. The last education is high school. The income is dominated Rp.1.100.000,00-Rp.2.000.000,00(2) The factors which push the citizen do mobility is the difficulty of developing business in the origin area and the limited educational facilities. The pull factor is the facilities, infrastructures and education in the destination area are more complete.(3) The mobility pattern dominated by Circular Mobility. The citizen in has been doing mobility for $1-5$ years. The distance is $1 / 2-1$ an hour.
\end{abstract}

Key words: The characteristic, factors, and pattern of non-permanent mobility. 


\section{PENDAHULUAN}

Menurut Razake

(1988)

mobilitas penduduk berlangsung melintasi batas ke ruang tertentu dan didorong oleh berbagai motivasi, serta untuk jangka waktu yang bervariasi, sedangkan Menurut Sumaatmadja dalam Wahyuni (2014) bahwa mobilitas penduduk adalah pergerakan penduduk dari satu tempat ketempat lain, baik untuk memenuhi kebutuhan ekonomi maupun untuk memenuhi kebutuhan sosial lainnya.

Desa yang mempunyai kecenderungan tinggi bermobilitas (permanen) adalah desa yang jaraknya relatif dekat dengan kotakota besar, distribusi penghasilan tidak merata proporsi petani tak bertanah tinggi, rendahnya ratio penduduk dan tanah, rendahnya proporsi penduduk yang mengetahui huruf, dekat jalan raya atau dekat dengan kota-kota kecil yang mempunyai kemudahan kontak dengan kota-kota besar dan mempunyai kemudahan untuk mendapatkan informasi mengenai daerah tujuan(Lipton dalam Wahyuni , 2014).

Berdasarkan pendapat di atas dapat penulis simpulkan bahwa mobilitas penduduk adalah pergerakan penduduk yang melewati batas ke ruang tertentu dalam jangka waktu yang bervariasi.

Gerak penduduk yang non permanen ini dapat pula dibagi menjadi dua yaitu ulang alik (commuting), dan dapat menginap atau mondok di daerah tujuan dalam batas waktu tertentu dan kembali ke daerah asal secepatnya sehingga kalau dibandingkan frekuensi penduduk yang melakukan mobilitas ulang alik, menginap/mondok, dan migrasi, frekuensi mobilitas penduduk ulang alik terbesar disusul oleh menginap/mondok diukur dari lamanya meninggalkan daerah asal lebih dari satu hari, tetapi kurang dari enam bulan, sedangkan mobilitas permanen diukur dari lamanya meninggalkan daerah asal lebih dari satu hari, tetapi kurang dari enam bulan (Mantra, 2009)

Perpindahan penduduk merupakan salah satu dari tiga faktor dasar yang mempengaruhi pertumbuhan penduduk, selain kelahiran dan kematian. Perpindahan penduduk dari suatu tempat ke tempat lain dengan tujuan tertentu disebut mobilitas. Pangaribuan dalam Wahyuni (2014).

Penggunaan batas wilayah dan waktu untuk indikator mobilitas penduduk mengikuti paradigma ilmu geografi yang mendasarkan konsepnya atas wilayah dan waktu (space and time concept). Batas wilayah umumnya digunakan batas administratif, misalnya provinsi, kabupaten, kecamatan, kelurahan (Mantra, 2009). Pada penelitian ini peneliti mengambil batas nagari, kecamatan, serta kabupaten sebagai batas administratif. 
Mobilitas penduduk non permanen ialah gerak penduduk dari satu wilayah ke wilayah lain dengan tidak ada niatan untuk menetap di daerah tujuan. Seseorang yang menuju daerah lain dan sejak semula sudah bermaksud tidak menetap di daerah tujuan, digolongkan sebagai pelaku mobilitas non permanen walaupun bertempat tinggal di daerah tujuan dalam jangka waktu cukup lama (Steele dalam Puspitasari, 2010).

Mobilitas sirkuler merupakan gerak berselang antara tempat tinggal dan tempat tujuan baik untuk bekerja maupun untuk lain-lain tujuan seperti sekolah dengan periode waktu tertentu umpanya seminggu, dua minggu, sebulan atau dengan pola yang kurang teratur diselang dengan kembali dan tinggal di tempat asal untuk waktu-waktu tertentu pula(Rusli,1983).

Berdasarkan observasi awal yang dilakukan di Nagari Canduang Koto Laweh,Mobilitas penduduk banyak dilakukan oleh penduduk yang berusia produktif dan penduduk yang masih melanjutkan pendidikan.Penduduk melakukan mobilitas mulai dari melewati batas nagari yaitu Nagari Lasi, batas kecamatan yaitu Kecamatan Ampek Angkek dan Kecamatan Baso, batas kabupaten yaitu Kabupaten Tanah Datar, Kabupaten 50 Kota dan batas provinsi yaitu Provinsi Riau.

Penduduk Nagari Canduang

Koto Laweh memiliki jenis pekerjaan beragam. Berdasarkan data yang didapat dari kantor wali nagari mayoritas penduduk nagari canduang koto laweh bekerja sebagai Petani (18\%). Dan minoritasnya adalah Anggota DPRD (1\%). Keberagaman pekerjaan akan membedakan status sosial ekonomi sehingga akan mendorong terjadinya pergerakan penduduk.

Masyarakat Nagari Canduang Koto Lawehterdiri dari sebelas jorong. Masing-masing jorong memiliki ciri dan karakteristik sendiri. Untuk keperluan bertani masyarakat yang sangat dekat dengan Gunung Merapi sudah mulai membuka lahan untuk bercocok tanam. Untuk hasil pertanian belum ada kemajuan karena keterbatasan SDA di nagari tersebut. Hasil panen langsung dijual di pasar, tanpa pengolahan lebih lanjut, seperti dijual ke pasar kecamatan dan pasar di Kota Bukittinggi. Di beberapa jorong potensi dan hasil pertanian juga berbeda, ada yang komoditinya berupa sayuran, padi, dan kayu manis. Akses menuju nagari ada angkutan desa. tetapi pelayanan/trayeknya tidak melayani seluruh jorong akibat lokasi jorong yang memiliki topografi yang terjal untuk menuju ke lokasi. Selain itu ada ojek tetapi tarifnyamahal. Nagari Canduang Koto Laweh juga berdekatan dengan kota besar yaitu Bukittinggi. Dekatnya suatu daerah dengan kota besar akan menyebabkan terjadinya pergerakan. 
Masyarakat Nagari Canduang Koto Laweh yang berpendidikan tinggi jarang yang menetap dan tinggal di kampung. Kebanyakan dari mereka setelah mendapatkan pendidikan tinggi memilih pergi untuk merantau.

Berdasarkan pengamatan dan observasi awal yang telah dilakukan penulis tertarik untuk melakukan penelitian tentang mobilitas penduduk di Nagari Canduang Koto Laweh Kecamatan Canduang Kabupaten Agam melalui sebuah penelitian dengan judul "Mobilitas non permanen penduduk Nagari Canduang Koto Laweh Kecamatan Canduang Kabupaten Agam Provinsi Sumatera Barat".

\section{METODE PENELITIAN}

Berdasarkan masalah dan tujuan penelitian maka peneliti menggolongkan penelitian ke dalam penelitian deskriptif dengan pendekatan kuantitatif, yaitu penelitian yang mendeskripsikan suatu gejala, fakta, peristiwa atau kejadian yang sedang atau sudah terjadi di masyarakat dan mengungkapkan fakta-fakta yang ada dengan angka-angka.

Penelitian deskriptif adalah penelitian yang diarahkan untuk memberikan gejala-gejala, faktafakta, atau kejadian-kejadian secara sistematis dan akurat, mengenai sifat-sifat populasi atau daerah tertentu (Zuriah, 2009). Berdasarkan pendapat di atas maka penelitian ini bertujuan untuk mendeskripsikan atau mengungkapkan data sebagaimana adanya tentang mobilitas penduduk non permanen di Nagari Canduang Koto Laweh, Kecamatan Canduang, Kabupaten Agam.

Batasan penelitian yang diambil yaitu nagari. Setiap masyarakat yang melakukan mobilitas non permanen melewati nagari dijadikan sebagai objek penelitian..

Menurut Hasan

populasi adalah totalitas dari semua objek atau individu yang memiliki karakteristik tertentu, jelas dan lengkap yang akan diteliti

Sugiyono

mengemukakan bahwa populasi adalah wilayah generalisasi yang terdiri atas: obyek/subyek yang mempunyai kualitas dan karaktersitik tertentu yang ditetapkan oleh peneliti untuk dipelajari dan kemudian ditarik kesimpulannya

Sampel adalah bagian dari populasi yang diambil melalui caracara tertentu yang juga memiliki karakteristik tertentu, jelas, dan lengkap yang dianggap bisa mewakili populasi. Mengenai jumlah sampel yang sesuai dalam suatu penelitian adalah sepersepuluh (10\%) dari seluruh populasi yang ada. Sampel dalam penelitian ini diambil dengan teknik random sampling yang ditetapkan sebesar $10 \%$ dari populasi yaitu berjumlah 9377 orang.

Menentukan besarnya sampel yang terpilih yang mempunyai 
jumlah penduduk sebesar 9377 orang dengan maksud untuk membatasi jumlah penduduk yang cukup besar, maka pengambilan sampel tersebut menggunakan teknik pengambilan sampel minimal dengan rumus:

$$
n=\frac{N}{1+N e^{2}}
$$

Dimana:

$\mathrm{n}$ = Besaran sampel

$\mathrm{N}=$ Besaran Populasi

$\mathrm{e}=$ nilai kritis (batas ketelitian).

Diketahui:

$\mathrm{N}=9377$

$\mathrm{e}=10 \%=0,1$

Maka diperolehn $=99$

Penelitian ini merupakan Penelitian Deskriptif sehingga tidak terdapat variabel bebas dan variabel terikat.

Adapun yang menjadi variabel dari penelitian ini adalah:

a. Karakteristik pelaku mobilitas penduduk non permanen

b. Faktor pendorong dan penarik mobilitas penduduk non permanen

c. Pola mobilitas penduduk non permanen
Data yang dikumpulkan dari penelitian berupa data primer dan data sekunder. Data primer: 1. Pekerjaan penduduk di daerah asal dan daerah tujuan, 2. Jumlah pendapatan penduduk, dan 3. Daerah tujuan pergerakan penduduk. Data sekunder yang digunakan adalah: 1 . Jumlah penduduk dan jumlah kepala rumah tangga dan 2. Kondisi geografis daerah penelitian.

Data primer diperoleh langsung melalui wawancara dengan responden yang mewakili populasi sedangkan data sekunder diperoleh dari situs resmi Kecamatan Canduang, Kantor Nagari Canduang Koto Laweh, serta kantor-kantor lain yang berkaitan dengan penelitian ini.

Alat pengumpulan data yang digunakan pada penelitian ini adalah kuesioner atau angket. Angket adalah sejumlah pertanyaan yang digunakan untuk memperoleh data dari responden dalam arti laporan tentang pribadinya atau hal-hal lain yang perlu diketahui.

Sesuai dengan alat pengumpul yang berbentuk kuesioner atau daftar pertanyaan penelitian ini menggunakan dua cara dalam mendapatkan data:

a. Menggunakan teknik wawancara untuk mendapatkan data primer.

b. Untuk responden yang memungkinkan kuesioner diserahkan langsung kepada responden . 
Teknik analisis data yang digunakan dalam penelitian ini adalah teknik persentase. Setelah semua data terkumpul, maka langkah selanjutnya adalah mentabulasikan jawaban responden. Sedangkan untuk mengolah data akhir, digunakan rumus statistik deskriptif berikut dengan formula:

$$
P=\frac{f}{n} \times 100 \%
$$

(Arikunto, 2010)

Ket:

$$
\begin{aligned}
& \mathrm{P}=\text { Persentase } \\
& \mathrm{F}=\text { Frekuensi (jumlah pilihan } \\
& \text { responden terhadap item) }
\end{aligned}
$$

$\mathrm{N}=$ Jumlah responden seluruhnya

Pola mobilitas penduduk non permanen dianalisis berdasarkan formula di atas yang akan dibuat dalam bentuk peta pola mobilitas penduduk non permanen.

\section{HASIL DAN PEMBAHASAN}

Penelitian ini membahas dan mendeskripsikan tentang karakteristik, faktor pendorong dan penarik, serta pola mobilitas non permanen penduduk Nagari Canduang Koto Laweh. Mobilitas non permanen terbagi menjadi dua yaitu ulang alik (komuter) dan nginap (sirkuler). Berdasarkan hasil penelitian dari 99 orang pelaku mobilitas non permanen terdapat 48 orang $(48,48 \%)$ yang melakukan mobilitas ulang alik, dan 51 orang $(51,51 \%)$ melakukan mobilitas Sirkuler.

\section{Karakteristik Penduduk}

Penduduk Nagari Canduang

Koto Laweh yang melakukan mobilitas non permanen adalah pada masa usia produktif. Pelaku mobilitas ulang alik didominasi oleh umur 35-44 tahun sebanyak 16 orang (33,33\%), sedangkan pelaku mobilitas sirkuler didominasi oleh umur 20-24 tahun sebanyak 28 orang $(54,90 \%)$, secara keseluruhan yang dominan melakukan mobilitas umur 20-24 tahun sebanyak 28 orang $(54,90 \%)$.

Pelaku Mobilitas Non Permanen penduduk Nagari Canduang Koto Laweh perempuan lebih banyak melakukan mobilitas berjumlah 55 orang $(55,55 \%)$, sedangkan laki-laki berjumlah 44 orang $(44,44 \%)$. Pelaku mobilitas jenis kelamin laki-laki lebih banyak melakukan mobilitas sirkuler berjumlah 24 orang $(47,05 \%)$. Sedangkan perempuan banyak melakukan mobilitas ulang alik berjumlah 28 orang $(58,33 \%)$.

Jenis pekerjaan penduduk yang melakukan mobilitas non permanen yaitu pedagang, guru honor, petani, buruh tani, pelajar, mahasiswa, pns, wiraswasta, dosen, karyawan, sopir, ojek. Adapun pelaku mobilitas penduduk non permanen yang 
dominan yaitu pada kelompok mahasiswa yaitu 32 orang $(32,32 \%)$, kelompok Wiraswasta 16 orang $(16,16 \%)$ dan karyawan berjumlah 12 orang $(12,12 \%)$, dan yang paling sedikit bekerja sebagai sopir dan ojek dengan jumlah 2 orang $(2,02 \%)$. Pelaku mobilitas ulang alik terbanyak adalah penduduk yang bekerja sebagai petani, pelajar, dan wiraswasta masing-masing sebanyak 8 orang $(16,67 \%)$. Dan bagi mahasiswa tidak ada yang melakukan mobilitas ulang alik. Sedangkan mobilitas sirkuler didominasi oleh mahasiswa sebanyak 32 orang $(62,74 \%)$, wiraswasta dan karyawan sebanyak 8 orang $(15,68 \%)$.

Penduduk di daerah asal yang pekerjaannya pedagang melakukan mobilitas karena alasan keterbatasan sarana perdagangan sehingga harus melengkapi kebutuhan perdagangannya ke daerah tujuan mobilitas.

Pendapatan penduduk sebelum melakukan mobilitas $<$ Rp.500.000,00 berjumlah 8 orang $(28,57 \%)$. Pendapatan $>$ Rp.500.000,00-Rp.1.000.000,00 berjumlah 16 orang $(57,14 \%)$, $>$ Rp.1.000.000,00 berjumlah 4 orang $(14,28 \%)$. pendapatan setelah melakukan mobilitas meningkat Pendapatan sebelum melakukan mobilitas terbanyak yaitu sebanyak 16 orang $(57,14 \%)$ pada rentang Rp.500.000,00-Rp.1.000.000,00, sedangkan pendapatan setelah melakukan mobilitas terbanyak pada rentang Rp.2.100.000,00Rp.3.000.000,00 sebanyak 10 orang $(35,71 \%)$.

Pelaku mobilitas non permanen rata-rata mengalami peningkatan pendapatan Rp.2.100.000,00Rp.3.000.000,00 sebanyak 14 orang (50\%), paling sedikit dengan peningkatan pendapatan Rp.100.000,00-Rp.1.000.000,00 sebanyak 3 orang $(10,71 \%)$, $>$ Rp.4.000.000,00 sebanyak 3 orang $(10,71 \%)$.

Pelaku mobilitas non permanen terdapat 50 orang $(50,50 \%)$ dengan pendidikan terakhir didominasi oleh SMA, dan paling sedikit pendidikan terakhir D3 sebanyak 3 orang $(3,3 \%)$. Pelaku mobilitas ulang alik pendidikan terakhir dominan SMP sebanyak 13 orang $(27,08 \%)$, sedangkan mobilitas sirkuler pendidikan terakhir dominan SMA sebanyak 40 orang $(78,43 \%)$.

Faktor pendorong dan penarik Mobilitas Penduduk Non Permanen di Nagari Canduang Koto Laweh

Faktor pendorong dan penarik Mobilitas Penduduk Non Permanen Nagari Canduang Koto Laweh meliputi faktor ekonomi, pendidikan dan sosial. Hal ini sesuai dengan teori Everett S.Lee dalam Mantra (2009) yang menyatakan faktor yang menyebabkan terjadinya mobilitas penduduk non permanen. Hal ini dilihat dari hasil penelitian bahwa 
alasan pelaku mobilitas yaitu sulit mengembangkan usaha di daerah asal, kualitas pendidikan yang bagus serta sarana perdagangan yang lengkap di tempat tujuan. Dari 99 responden ada 32 orang yang mengungkapkan alasan melakukan mobilitas non permanen karena untuk memperoleh pendidikan yang lebih tinggi di daerah tujuan.

Hasil penelitian diatas sesuai dengan pendapat Adioetomo (2010) yang menyatakan banyak faktor yang mempengaruhi mobilitas penduduk anatara lain : Faktor dari daerah asal yang disebut faktor pendorong seperti adanya tekanan dari daerah asal, tidak cocok lagi dengan masyarakat, alasan pekerjaan. Faktor yang ada di daerah tujuan yang disebut faktor penarik seperti tersedianya lapangan kerja, faktor pendorongnya adalah tidak cocok lagi dengan adat istiadat dan lingkungan masyarakat, tingkat pendapatan yang rendah di daerah asal, sulit mengembangkan usaha di daerah alasan pekerjaan, tidak adanya pasar nagari di daerah asal.

Faktor dari daerah asal yang disebut faktor penarik yaitu kesempatan untukmemperoleh kesempatan kerja yang cocok, kesempatan memperoleh pendidikan yang lebih tinggi, keadaan lingkungan dan keadaan hidup yang menyenangkan di daerah tujuan, tarikan dari orang yang diharapkan sebagai tempat berlindung dan adanya aktivitas-aktivitas di kota besar. Sedangkan pada hasil penelitian faktor penariknya adalah kesempatan untuk memperoleh kesempatan kerja yang cocok, kesempatan memperoleh pendidikan yang lebih tinggi, keadaan lingkungan, keadaan hidup yang menyenangkan di daerah tujuan, dan kualitas pendidikan yang bagus di daerah tujuan.

\section{Pola Mobilitas Penduduk Non Permanen Nagari Canduang Koto laweh}

Pergerakan penduduk pada regional ini paling sedikit yaitu sebanyak 5 orang (100\%). Peta pola mobilitas penduduk dapat dilihat pada gambar 1 . 


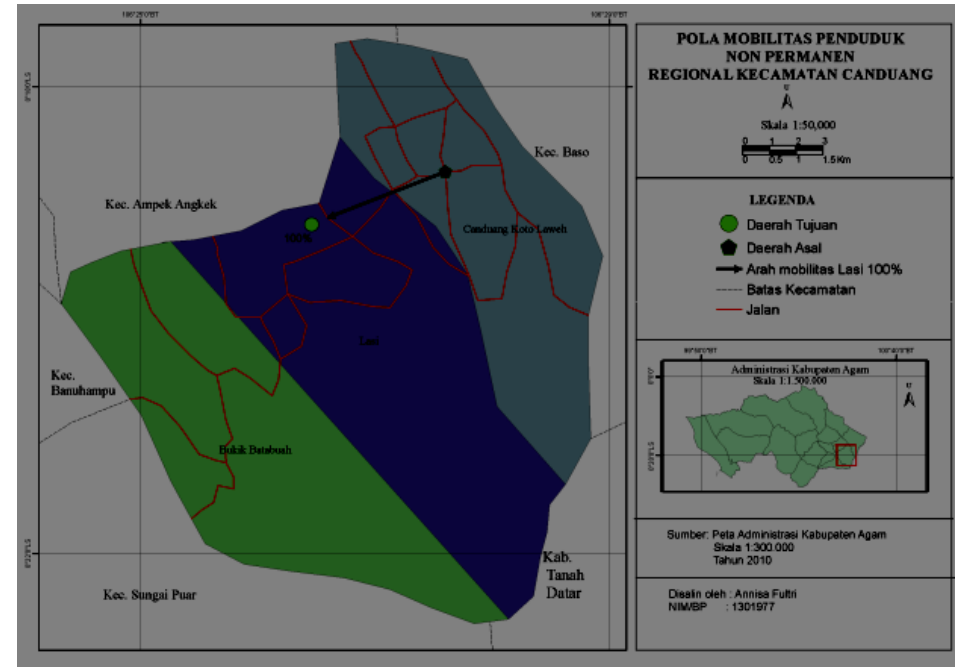

Gambar 1. Peta pola mobilitas non permanen regional Kecamatan Canduang

Penduduk Nagari Canduang Koto Laweh melakukan mobilitas non permanen pada regional kabupaten lebih banyak pada daerah Bukittinggi berjumlah 30 orang $(56.60, \%)$. Peta pola mobilitas penduduk dapat dilihat pada gambar 2 . 


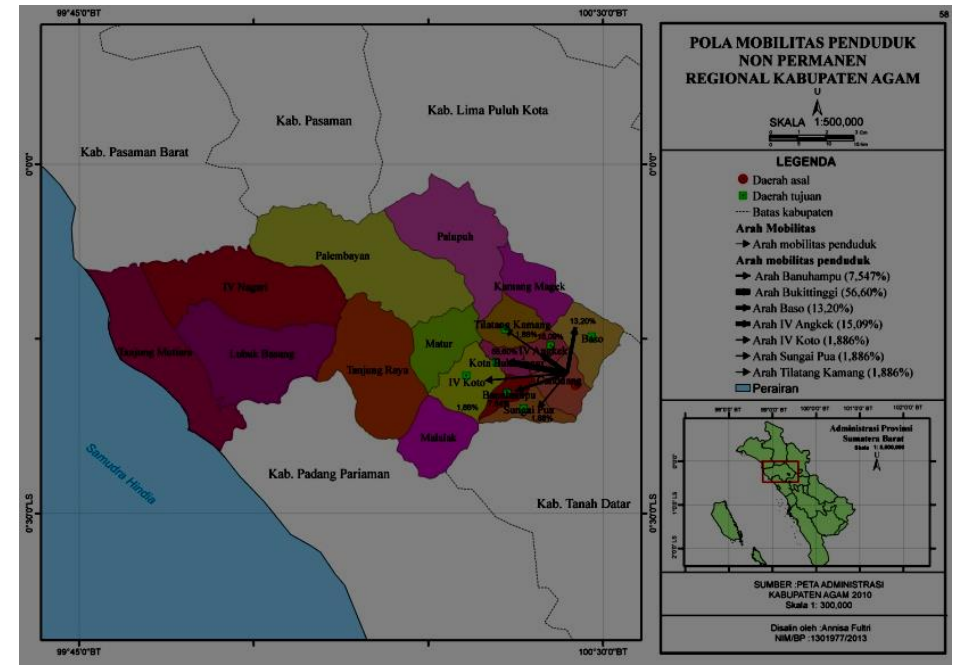

Gambar 2. Peta pola mobilitas non permanen regional Kabupaten Agam

Penduduk Nagari Canduang

Koto Laweh pelaku mobilitas non permanen pada regional Provinsi lebih banyak melakukan mobilitas ke Kota
Padang berjumlah 16 orang (64\%).

Peta pola mobilitas dapat dilihat pada gambar 3. 


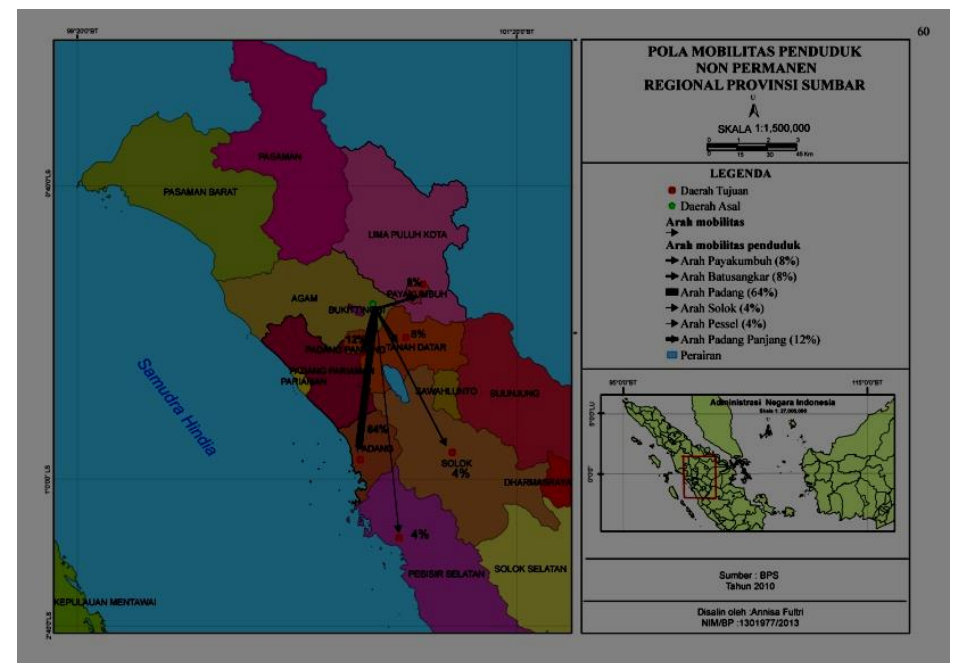

Gambar 3. Peta pola mobilitas non permanen regional Provinsi Sumatera Barat

Nagari Canduang Koto Laweh banyak melakukan mobilitas non permanen pada daerah tujuan Pekanbaru berjumlah 5 orang $(31,25 \%)$. Peta pola

mobilitas regional provinsi dapat dilihat pada gambar 4 . 


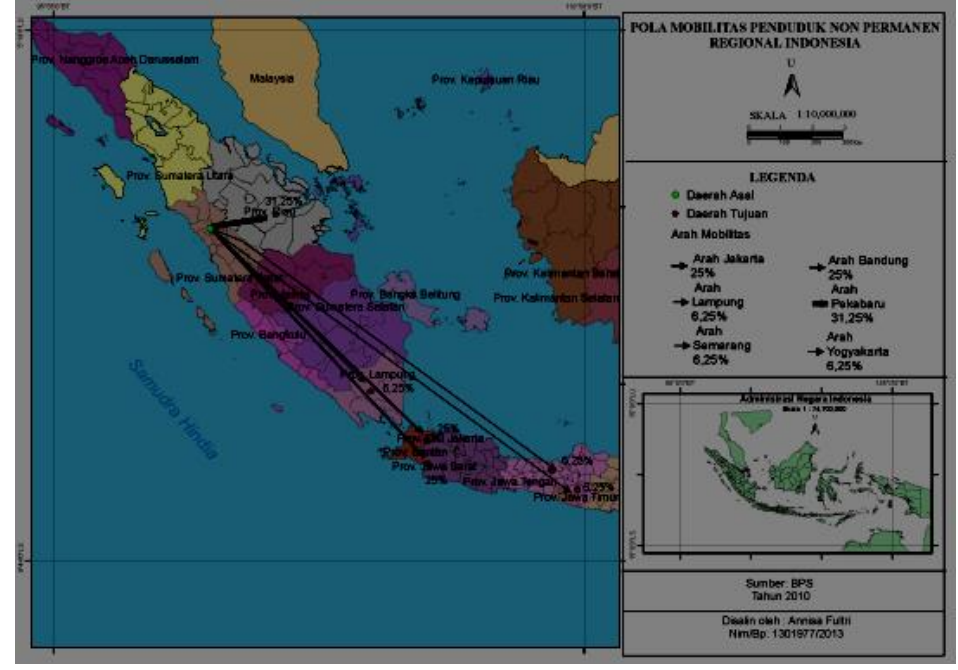

Gambar 4. Peta pola mobilitas non permanen regional Indonesia. 
Berdasarkan hasil penelitian dapat diketahui bahwa pelaku mobilitas non permanen penduduk Nagari Canduang Koto Laweh pada umumnya bermobilitas ke daerah tujuan yang masih dalam satu regional kecamatan dan provinsi, sedangkan yang menuju wilayah diluar provinsi ada dalam jumlah yang sedikit. Hal ini sesuai dengan pendapat Mantra (2009) yaitu penggunaan batas wilayah dan waktu untuk indikator mobilitas penduduk mengikuti paradigma ilmu geografi yang mendasarkan konsepnya atas wilayah dan waktu (space and time concept). Batas wilayah umumnya digunakan batas administratif, misalnya provinsi, kabupaten, kecamatan, kelurahan.

Pelaku mobilitas non permanen paling banyak dengan rentang waktu 1-5 tahun dengan frekuensi mobilitas dominan harian. Sedangkan mingguan lebih sedikit dibandingkan bulanan karena daerah tujuan mobilitas dominan diluar regional kabupaten. Hal ini sesuai dengan pendapat Mantra (2009) melihat adanya hubungan terbalik antara jarak dengan intensitas hubungan. Semakin dekat tempat tinggal migran, semakin tinggi frekuensi kunjungan ke daerah asal, dalam migrasi kaidah ini disebut dengan kaidah "distance decay". Intensitas hubungan ini sudah tentu mempengaruhi pula intensitas dampak mobilitas di pedesaan atau daerah asal tersebut.

Tabel 1. Frekuensi pelaku mobilitas non permanen Penduduk Nagari Canduang Koto Laweh tahun 2017

\begin{tabular}{|c|l|r|c|}
\hline No & $\begin{array}{c}\text { Frekuensi } \\
\text { mobilitas }\end{array}$ & F & $\%$ \\
\hline 1 & Harian & 47 & 47,47 \\
\hline 2 & Mingguan & 23 & 23,23 \\
\hline
\end{tabular}

\begin{tabular}{|l|l|r|r|}
\hline 3 & Bulanan & 29 & 29,29 \\
\hline & Jumlah & 99 & 100 \\
\hline
\end{tabular}

Sumber:pengolahan data primer 2017

Keadaan ini sesuai dengan pendapat mobilitas sirkuler menurut Rusli (1983) yaitu merupakan gerak berselang antara tempat tinggal dan tempat tujuan baik untuk bekerja maupun untuk lain-lain tujuan seperti sekolah dengan periode waktu tertentu umpamanya seminggu, dua minggu, sebulan atau dengan pola yang kurang teratur diselang dengan kembali dan tinggal di tempat asal untuk waktuwaktu tertentu pula.

Penduduk Nagari Canduang Koto Laweh melakukan mobilitas non permanen paling tinggi pada jarak 1/2-jam berjumlah 53 orang $(53,53 \%)$, dan paling rendah pada jarak $<1 / 2$ jam berjumlah 5 orang $(5,05 \%)$. Hal ini sesuai dengan pendapat Ravenstain dalam Mantra (2009) bahwa para migran cenderung memilih tempat terdekat sebagai daerah tujuan.

Pelaku mobilitas non permanen Nagari Canduang Koto Laweh lebih banyak menggunakan kendaraan umum berjumlah 59 orang $(59,59 \%)$, sedangkan kendaraan pribadi berjumlah 40 orang $(40,40 \%)$, dalam menentukan pilihan jenis angkutan, orang mempertimbangkan berbagai faktor, yaitu maksud perjalanan, jarak tempuh, biaya, dan tingkat kenyamanan.

Penduduk Nagari Canduang Koto Laweh pelaku Mobilitas Non Permanen paling banyak mengeluarkan biaya Rp.3000,00-Rp.29.000,00 berjumlah 61 orang $(61,61 \%)$, dan paling sedikit biaya Rp.60.000,00 - Rp.89.000,00 berjumlah 3 orang $(3,03 \%)$.

\section{KESIMPULAN}


Dari paparan hasil penelitian, kesimpulan yang dapat diambil dari penelitian ini adalah sebagai berikut:

Karakteristik penduduk Nagari Canduang Koto Laweh yang melakukan mobilitas penduduk non permanen meliputi usia, jenis kelamin, pekerjaan, pendapatan, dan pendidikan dari segi usia, dan penduduk yang melakukan mobilitas non permanen lebih didominasi oleh usia produktif yaitu antara 15-64 tahun yang lebih banyak dilakukan oleh perempuan dari pada laki-laki. Dari segi pekerjaan pelaku mobilitas non permanen Nagari Canduang Koto Laweh dapat diklasifikasikan menjadi kelompok Mahasiswa, pelajar, PNS, guru honor,petani,buruh tani, pedagang, wiraswasta, dosen, sopir, tukang ojek dan karyawan. Dari segi pendidikan, pendidikan terakhir pelaku mobilitas penduduk non permanen bervariasi mulai dari tamat SD hingga S1 dan S2, namun yang dominan pendidikan terakhirnya adalah SMA. Pendapatan pelaku mobilitas dominan Rp 1.100.000,00 - Rp.2.000.000,00 17 orang $(28,81 \%)$,

Faktor yang mendorong penduduk untuk melakukan mobiltas non permanen di Nagari Canduang Koto Laweh meliputi faktor pendidikan dan ekonomi yaitu karena sulit mengembangkan usaha di daerah asal dan keterbatasan sarana pendidikan. Sebaliknya, faktor penarik adalah karena sarana dan prasarana di daerah tujuan lebih lengkap dan pendidikan di daerah tujuan lebih lengkap.

Pola Mobilitas Penduduk Non Permanen Nagari Canduang Koto Laweh yaitu Pola mobilitas harian, mingguan, dan bulanan yang didominasi Mobilitas Sirkuler. Dengan daerah tujuan melewati batas administrasi nagari, kecamatan, kabupaten dan provinsi. Rata-rata penduduk Nagari Canduang Koto Laweh sudah melakukan mobilitas non permanen selama 1-5 tahun. Jarak dari daerah asal ke daerah tujuan pelaku mobilitas yang dominan adalah menempuh jarak 1/2-1jam dan masih dalam regional kabupaten.

\section{SARAN}

Karena pelaku mobilitas penduduk non permanen Nagari Canduang Koto Laweh ada yang bekerja sebagai petani Wartel dapat dikembangkan dengan melakukan pengelolaan Wartel menjadi produk yang bervariasi. Agar dapat membuka lapangan pekerjaan di daerah asal. Sehingga penduduk dapat melakukan aktivitas didaerah asal.

Hendaknya sarana prasarana penunjang mobilitas penduduk non permanen yang didorong oleh faktor pendidikan dapat ditingkatkan.

Karena pada umumnya pelaku mobilitas penduduk non permanen melakukan mobilitas melewati batas administrasi nagari, kecamatan, kabupaten dan menempuh jarak yang jauh seharusnya tetap berinteraksi dengan masyarakat setempat dan dapat membangun Nagari Canduang Koto Laweh khususnya bagi para pelajar dan mahasiswa yang telah mengenyam pendidikan di daerah lain agar dapat berpartisipasi di daerah setempat.

Kepada pemerintah Nagari agar dapat mengontrol mobilitas penduduk setempat sehingga mudah untuk mendata jumlah pelaku mobilitas.

\section{DAFTAR PUSTAKA}

Abdul Aziz Razake, 1988. "Pengantar Kependudukan dan Lingkungan Hidup" FKIP.Universitas Haluoleo. 
Adioetomo, Sri Moertiningsih, dan Omas Bulan Samosir, 2010. "Dasar-Dasar Demografi” Jakarta: Salemba Empat. Arikunto Suharismi, 2010. "Manajemen Penelitian".Jakarta: Rineka Cipta.

Hasan Iqbal, 2008. "Pokok-Pokok Materi Statistik 2".Jakarta: Bumi Aksara.

Mantra Ida Bagoes, 2009. "Demografi Umum", Yogyakarta: Pustaka pelajar. Puspitasari, Ayu Wulan. 2010. Jurnal Migrasi. Analisis Faktor yang Mempengaruhi Minat Sirkuler ke Kabupaten Semarang. Semarang: Universitas Diponegoro

Rusli Said. 1983. "Pengantar Ilmu Kependudukan", Bogor: Pustaka LP3ES Indonesia.

Sugiyono, 2012. "Metode Penelitian Kuantitatif Kualitatif dan $R \& D$ ”. Bandung: Alfabeta.

Wahyuni Sri, 2014. "Studi Tentang Mobilitas Penduduk di Kelurahan Sempaja Selatan Kecamatan Samarinda Utara Kota Samarinda."Jurnal Ilmu Pemerintahan. Vol 2 No 1 Hal 113.

Zuriah Nurul, 2009. "Metodologi Penelitian Sosial dan Pendidikan". Jakarta: Bumi aksara. 